\author{
Fujino Hanako \\ Oxford Brookes University
}

\title{
L2 Learners' perceptions of grammar: the case of JFL learners in the UK
}

\begin{abstract}
This study reports on the findings of a questionnaire administered to 93 students studying Japanese as a foreign language (JFL) at British universities, focusing on their views of the role of grammar in their learning of Japanese. Learners' views are important because mismatches with their teachers' views can affect their learning negatively. Following previous studies, the learners in this study, who were at upper-beginner to lower-intermediate levels, valued formal instruction and wanted teachers to give detailed explanations on grammar. In particular, their views suggested that they seek greater understanding of the semantic and pragmatic features of new grammatical structures. We suggest that particularly in the case of a 'less familiar' language such as Japanese, anglophone learners can benefit from a 'focus on forms' approach that incorporates different learning processes such as pattern recognition and making associations, alongside a 'focus on form' approach that assists their understanding of how the target grammatical structures are used in context.
\end{abstract}

Keywords: learners' perception; form-focused instruction; Japanese as a foreign language

\section{Introduction}

Pedagogic grammar - understood here as the grammar of an L2 designed to help learners develop their mastery of the $L 2$ - has long been the subject of controversy. It is a feature particularly of 'traditional' language teaching approaches but teachers and researchers are still divided as to the role it plays in instructed adult second language acquisition. In what follows, we investigate the views of students; anglophone university students studying Japanese, considered generally to be a particularly demanding language for native speakers of English. Furthermore, the teaching of Japanese as a foreign language has typically been conducted using 'traditional' form-focused approaches associated with the so-called Grammar-Translation and Audiolingual methods. In such a context, do these students find a focus on grammar to be a help or a hindrance?

We begin by reviewing some of the key issues that have been raised in investigating the role of grammar in the L2 classroom. We then review research on teacher and learner views of grammar and highlight the potentially negative effect of mismatches of beliefs and expectations between teachers and learners. To provide further details of the context of this study, we look briefly at a typical treatment of grammatical structure in the two most widely used JFL textbooks. From there, we present our exploratory research, based on an easy-to-administer online questionnaire focusing on learners' beliefs and preferences in relation to different aspects of grammar teaching. 


\section{The teaching and learning of grammar in the L2 classroom}

For many, pedagogic grammar is seen as a collection of prescriptive rules indicating whether a grammatical form is correct or not. Such rules have been instrumental in standardising languages, and it can be argued that they simplify language learning, both for the teacher and the learner. However, they have also often been criticised as arbitrary and they are liable to change as language evolves (Odlin 1994). Pedagogic grammar can also be descriptive, aiming to account for authentic target language (TL) use and to enable $L 2$ learners to notice and analyse language input. There is certainly a tension between these prescriptive and descriptive functions. On the one hand, pedagogic grammar needs to be simple and restrictive in order to enable learners to understand and produce TL structures; on the other, it needs to be broad enough to account for real language use. It needs to be such that it helps learners convert declarative knowledge of the L2 into an 'internalised system', in other words, knowledge that can support fluent use.

The term 'grammar' for the learner is also ambiguous. On the one hand, it refers, as we mentioned above, to the explicit knowledge of grammatical rules, i.e., the declarative knowledge over which the learner is expected to develop some mastery. Grammar thus understood can serve as a metacognitive tool that provides the learner with the framework necessary to organise the complex information that they receive from TL input, as well as to allow them to articulate and understand their learning (see Broady and Dwyer 2008 for overview). On the other hand, it refers to implicit knowledge, i.e., what we refer to above as the internalised system. This knowledge is formed through the gradual process of language acquisition and is not necessarily accessible to conscious control. The relationship between these two concepts of grammar - in particular, how explicit knowledge affects implicit knowledge - is a longstanding debate. The widely accepted view at present seems to be that explicit knowledge can facilitate the development of implicit knowledge (Norris and Ortega 2000; R. Ellis 2006 for overview) and the relationship has been described as 'dissociable but cooperative' (N. Ellis 2005). However, with regards to grammatical instruction, there is still uncertainty about when is best to provide it, and what is the most effective way to do so (R. Ellis 2006). This is due to the inevitable fact that language learners have different backgrounds and learning styles, and language learning can take place in very different circumstances with different objectives and different levels of exposure to the TL.

Grammatical instruction, often referred to now as 'form-focused instruction' $(\mathrm{FFI})$, can be defined as 'any planned or incidental instructional activity that is intended to induce language learners to pay attention to linguistic form' (R. Ellis 2001: 1-2). Traditionally, grammar has been taught deductively, and often in the learners' shared L1 rather than in the TL. The classic classroom approach to FFI is often referred to as PPP or presentation-practice-production. Grammatical structures are typically taken out of authentic communicative context and presented in the form of rules (in the GrammarTranslation method) and/or in the form of illustrative examples (preferred by the later Audiolingual method), and then practised through mechanical exercises and drills such as rewriting, gap-filling, transformation exercises, and in the case of GrammarTranslation, by translation of sentences from L1. Learners are then - and only then - 
given the opportunity to produce the structure in some kind of limited context, usually tightly defined by the teacher or teaching materials. (For detailed discussion of different methods and approaches, see Richards and Rodgers 1985 and Klapper 2005).

Notice that in the PPP method, there is an assumed hierarchy that form precedes meaning. The mechanical exercises during the practice phase are meant to help learners consolidate and automatise rules regarding structural or morphosyntactic properties so that they can then focus on meaning in the following production phase. Learning the form and the meaning separately, it has been argued, may make some sense from a processing point of view, as learners, in particular those at beginner level, may well have difficulty attending to both (VanPatten 1990). The PPP method is still widely used in many classrooms; however, it has been criticised for the fact that students who learn by this method often fail to apply learnt grammar in communication despite knowing the rules explicitly, what Larsen-Freeman (2003) refers to as the 'inert knowledge' problem. Mechanical exercises have also been criticised in that they arguably do little to help learners develop real understanding (declarative knowledge) of the target structure (DeKeyser 1998). They typically lack meaningful contexts (Celce-Murcia 2007) and fail to engage learners in anything resembling authentic TL behaviour (Larsen-Freeman 2014).

The shift to Communicative Language Teaching (CLT) in the 1970's brought a radical change in the treatment of grammar, with 'communicative competence' (i.e. the ability to communicate in the TL, rather than have accurate knowledge of it) becoming the aim. Proposals such as the Natural Approach (Krashen 1981, 1985) claimed that L2 grammar was acquired implicitly as in first language acquisition, and all that the learner needed was comprehensible input and a low affective filter. The focus of FL teaching was now on meaning, rather than form, and it was argued that instruction - and indeed all communication in the classroom - should take place in the TL in order to maximise learners' exposure to comprehensible input. Whilst weaker versions of CLT maintained that some attention to grammar might be helpful for successful learning, stronger versions of CLT argued that the focus should at all times be on 'meaning' as 'form' would be learned implicitly through the act of negotiating meaning.

However, studies on the development of grammatical accuracy in immersion programmes suggested that comprehensible input and negotiation of meaning alone did not guarantee native-like grammatical development (Swain 1985; Harley 1989). Evidence also suggested that when grammar-based courses were taken alongside oral communication courses, learners increased their grammatical accuracy more than through just practising oral communication (Montgomery and Einstein 1985). Such findings led to the view that some form of FFI could be supportive of L2 language development.

There is now a wide consensus that grammar should be taught, not as an end in itself but embedded in otherwise meaning-focused activities (Long 1991; Celce-Murcia 1990; Mitchell 2000). Encountering grammatical issues in the course of working out meaning is said to help learners notice linguistic features, i.e., 'consciousness-raising' (Rutherford and Sharwood Smith 1985), and to help them notice gaps between what they already know and what they need to learn, i.e. 'the notice-the-gap principle' (Schmidt and Frota 1986). Conscious attention to specific linguistic features has been argued to increase the chances of 'input' becoming 'intake', that is, part of the learner's implicit TL knowledge that can be used in language use. 
FFI given within a communicative context is widely referred to as 'focus on form (FonF)'. The term was coined by Long (1991) who defined it as FFI that 'overtly draws students' attention to linguistic elements as they arise incidentally in lessons whose overriding focus is on meaning or communication' (Long 1991: 45-46, via R. Ellis 2016). Long's version of FonF is reactive in that the main focus remains on communicative activities and FFI is given briefly only when the need arises in order to help learners use the language more accurately. Larsen-Freeman (2014), however, takes a much wider view of FFI and proposes a three-dimensional grammar framework comprising 'form,' 'meaning,' and 'use' (Larsen-Freeman 1999, 2001). 'Form' is concerned with the morphosyntactic and lexical patterns of the target structure, 'meaning' is concerned with its semantic features, and 'use' is concerned with the pragmatic features that determine when or why a speaker/writer chooses a particular form over another in a given context. The three dimensions are non-hierarchical, and she argues that any FFI needs to address all three. Drawing on evidence from corpus linguistics, she defines 'grammar' as 'a system of lexicogrammatical patterns that are used to make meaning in appropriate ways' (Larsen-Freeman 2014: 258). Given that language is dynamic and constantly evolving, she suggests that a more efficient form of FFI may be to help learners recognise the patterns in context of a particular grammatical construction instead of teaching them a list of rules that, as we mentioned earlier, may often be arbitrary.

With regard to the learning process, Larsen-Freeman (2014) explains that grammar constructions are not acquired one at a time but rather, different aspects of the same construction are acquired at different stages of L2 development. Therefore, contrary to what a typical structural syllabus assumes, learners may not be able to produce a construction just because they have been taught it and they often make errors even after they appear to have mastered it. Similarly, grammar learning is an iterative process and it is necessary to recycle and revisit grammar constructions as the need arises. Finally, when learners engage with new grammar, they are likely to rely on existing knowledge and experience. Beginner-level learners rely heavily on their L1 as their knowledge of L2 is still scarce, and only as they become more advanced, can they rely more on the $\mathrm{L} 2$. Therefore, an advantage of a FL classroom where the students have a shared L1 is that teachers can make associations and comparisons with the shared L1 to support their students' early learning.

Teachers of course have different preferences for the presentation of grammar. Some explain rules using examples, while others explain the rules first and invite the students to interpret the examples for themselves. Such a deductive approach aims to equip learners with accurate declarative understanding of the target structure. Other teachers may take a more inductive approach and ask students to analyse examples and try to formulate their own understanding of the target structure. This approach seeks to develop learners' autonomous analytic thinking and encourage learners to 'discover' grammar in input they are exposed to. There seems to be growing support among teachers for the inductive approach (S. Borg and Burns 2008), but research on methodology has not yet reached a clear conclusion about whether or not it is more effective to teach grammar deductively or inductively (Erlam 2003). Learners, it seems, are often somewhat resistant to the inductive approach, as we will see below. 


\section{Second language learners' beliefs on language learning}

Numerous studies since the 1980's have explored learners' beliefs about language learning in an attempt to identify to what extent, and in what ways, their mental orientation might influence their learning. 'Belief' is understood as 'a proposition which may be consciously or unconsciously held, is evaluative in that it is accepted as true by the individual, and is therefore imbued with emotive commitment; further, it serves as a guide to thought and behavior' (M. Borg 2001: 186). Beliefs are considered to relate to learners' use of learning strategies (Yang 1999) and to influence their overall achievement in foreign language (FL) learning (Mori 1999). In particular, it is widely agreed that beliefs matter because mismatches between what learners believe and expect, and what the language teacher believes and brings into the classroom can negatively affect learning.

Belief studies took off in the late 1980s after Horwitz's development of the Beliefs About Language Learning Inventory (BALLI). Based on this questionnaire, Horwitz (1988) found that US students starting language learning typically believed that FL learning was mostly a matter of memorising a lot of vocabulary and grammar rules, and more than $60 \%$ of her sample thought that it was merely a matter of translating from the mother tongue. When Kern (1995) compared student and teacher beliefs, he found that students tended to believe more than teachers that language learning was mostly a matter of learning a lot of grammar rules. Both studies cautioned that such mismatches could lead to students experiencing anxiety, loss of motivation, and even attrition. They advocated that teachers should discuss with their students the nature of language learning and the benefits of their approaches in order to clarify expectations.

Several studies have focused specifically on learners' beliefs about grammar and grammatical instruction, and many have found that learners in general report that they value grammatical instruction considerably more than teachers do (Schulz 1996, 2001; Peacock 1998; Hawkey 2006; Liao and Wang 2009; Loewen et al. 2009). Schulz (1996) compared the views on the role of grammatical instruction and error correction of 824 students who were in their first three weeks of FL learning, and 92 teachers of various languages. The study found that regardless of the $T L$, students were favourably disposed towards grammatical instruction and believed that it was necessary in order to master a language. Teachers, on the other hand, believed more than students that it was better to study grammar in real-life situations rather than to study forms explicitly. Peacock (1998) also observed that students favoured error correction and grammar exercises more than their teachers. Loewen et al. (2009) similarly found that 754 American students enrolled in different FL courses at various levels generally considered grammar to be the foundation of language learning, and that studying grammar was useful for improving other language skills such as speaking or writing. Some students expressed that they enjoyed studying grammar, in particular, exploring the rules and discovering the patters in the TL. However, a large proportion of students $(25 \%)$ said that they did not like grammar because it was boring, tedious, and monotonous. They preferred grammar to be related to real-life situations. With regard to how they preferred to be taught grammar, more than $15 \%$ referred to the use of examples, suggesting that seeing many examples of how the target grammar is used was helpful. Similarly, there was a desire for more explanations on when and where a target structure should be used. The students did not like to be left on their own when studying grammar. In particular, they did not like being asked to figure out the rules by themselves and they found it difficult 
to understand them by reading the textbook. They were also reluctant to memorise a list of grammatical rules.

These studies suggest that learners typically value explicit knowledge of grammar, certainly more than their teachers. This is perhaps because students see grammar as something that they can potentially understand and control in a formal learning environment, where tangible results ('correct' answers to controlled practice exercises such as those exemplified below) can give a sense of satisfaction. This may also be linked to the more general belief that language is learned by memorising rules and vocabulary. The difficulty and reluctance that learners nevertheless experience in understanding grammatical rules reflects the tensions regarding the prescriptive and descriptive functions of pedagogic grammar; pedagogic grammar, as it is often presented, may not allow learners to easily understand - or potentially use - new grammatical structures, and learners thus come to depend on their teachers' explanations to complement it.

According to research on teachers' perceptions of the role of grammar and grammar teaching, teachers are quite aware of the fact that students expect to be taught 'grammar' and in fact, students' views have a large influence on their decisionmaking regarding grammar teaching (S. Borg 1998; Burgess and Etherington 2002; Macrory 2000). Burgess and Etherington (2002) found that many of the English for Academic Purposes teachers they surveyed believed that grammatical instruction and discussions on grammar were useful to students and helped them improve their accuracy, while at the same time believing that languages could be learned 'naturally' from exposure. Teachers also felt that there was a gap between students' explicit knowledge of grammar and their ability to use it. The above suggests that whilst teachers are aware of students' needs about grammatical instruction, their own beliefs about language learning tend to be geared towards a naturalistic view. They tend to believe that creating opportunities to develop implicit knowledge of grammar leads to students' greater fluency, rather than improving explicit grammatical knowledge. Explicit knowledge of grammar is thus a limited tool to articulate and analyse the syntactic and morphological aspects of language.

\section{Grammar learning in the JFL classroom}

Japanese is considered to be a particularly difficult language to master for native speakers of English. The US Foreign Service Institute places it in the most difficult category, where more than 2200 class hours are required to become fluent, as compared to 600 hours for languages that are closer to English such as French or German. Consequently, it seems important that any mismatches in expectations between learners and teachers of Japanese are kept to a minimum so that learning is made as efficient as possible. Given that learners often perceive 'grammar' to be the foundation of their language learning, a step towards achieving this efficiency might be to understand where mismatches potentially lie in this area, and to gain some understanding of students' views of 'grammar'. A cursory look at the comments on a website for Japanese learners ${ }^{1}$ suggests that anglophone learners frequently consider the structural differences between English and Japanese to be their primary challenge: as one learner put it, 'If English is your first language you might have a hard time getting 
over the fact that the words you're using have no English equivalent and that the sentence structure is often completely backwards.'

Despite this high level of difficulty, the demand of Japanese in the UK has been growing steadily. According to the Japan Foundation, there were over 20 thousand students studying Japanese in institutional settings in 2015, a 50\% increase from 2003 $(13,336$ students). Of these, 6,423 (32\%) were studying Japanese in higher education either as part of their degree or as an elective language.

The teaching of Japanese as a foreign language in higher education in Europe has been going through transition over the past 15 years in order to adapt to the Common European Framework of Reference for Languages (CEFR). In many institutions, can-do statements have been adopted to describe learning objectives more in terms of language use than language knowledge (i.e. knowledge of grammatical structures), and courses have been defined by the CEFR with a greater emphasis on communicative use and student-centred learning. This has improved the articulation of proficiency levels and facilitated the placement of students in study-abroad programmes, at least within Europe.

Nevertheless, the approach in textbooks and other pedagogical materials for JFL remains fairly traditional, broadly reflecting a structural approach. According to the Japan Foundation (2015), Minna no Nihongo (3A Corporation) and Genki (Japan Times) are the most commonly used JFL textbooks and they influence strongly how Japanese grammar is taught in the UK. Both textbooks employ a structural syllabus, with grammatical structures typically taught deductively using a PPP sequence. For example, in Lesson 35 of Minna no Nihongo Shokyu volume 2 (3A Corporation 2013), the conditional form - $b a$ is introduced. In the presentation phase, students are shown the conjugation table of this form and some example sentences using it. Minna no Nihongo also has a companion book called Translation and Grammar Notes where explanations of the target grammatical structures are given. Then in the following practice phase, simple mechanical exercises are provided, requiring transformation and/or integration of structural elements as in the example below:

Rei: Mainichi nihongo-de hanashimasu. Motto jouzuni narimasu.

Example: (You) speak in Japanese every day. (You) will become even better.

-> Mainichi nihongo-de hanaseba, motto jouzuni narimasu.

-> If (you) speak in Japanese every day, (you) will become even better.

1. Ojiisan-ni kikimasu. Mukashi-no koto-ga wakarimasu.

(You) ask the old man. (You) will learn about the old days.

Rei: Ryou-de paatii-ga dekimasu-ka. (Kyoka-o moraimasu)

Example: Can (I) have a party in the dormitory? (To get permission)

-> Ee, kyoka-o moraeba, dekimasu.

$\rightarrow$ Yes, if (you) get permission, (you) can.

2. Fujisan-ni noboremasu-ka. (7-gatsu-ni narimasu)

Can (I) climb Mt. Fuji? (It is July)

(3A Corporation 2013: 79-80)

It is hard to imagine these exercises as examples of real communication. Exercise 1 is clearly divorced from any sense of a communicative task. Exercise 2 might be considered 
to have greater communicative value because it forms a question-answer exchange. However, it is clear that the overriding aim for both these TL examples is simply to get learners to practise the -ba form. It is not clear what kind of condition the -ba form denotes nor the real contexts where it is likely to be used; in other words, there is little opportunity here for exploring two of Larsen-Freeman's (2014) three key elements in her pedagogic grammar framework: 'meaning' and 'use', or the semantic and pragmatic values of the structure. Finally, in the production phase, there are short dialogues for learners to practise in pairs, as shown below. In the following exercise, learners should substitute the phrases in brackets 1 and 2 with the phrases in c. 1 and c. 2 respectively.

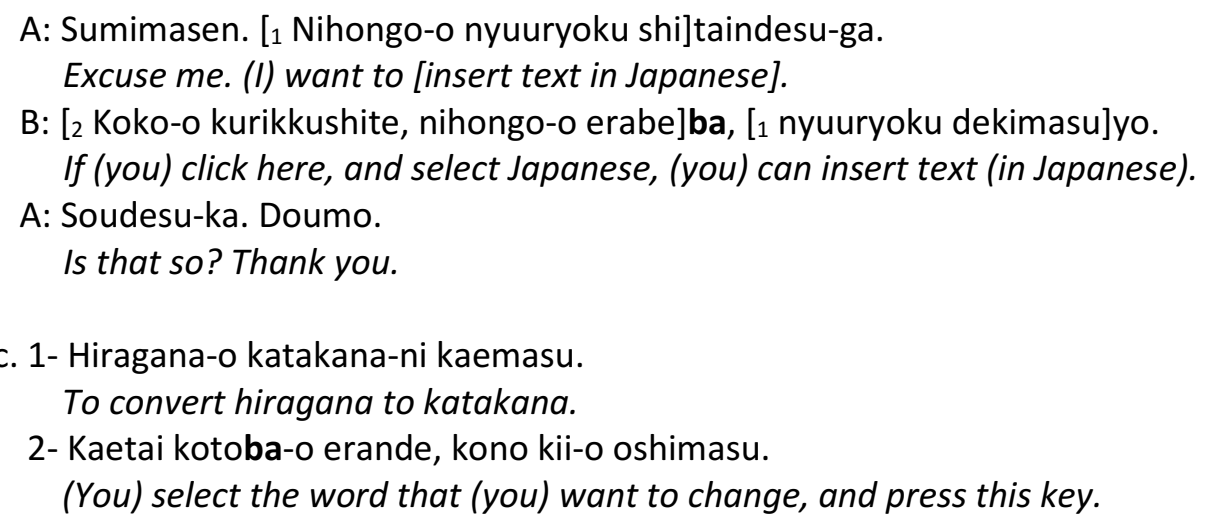

(3A Corporation 2013: 81)

The dialogues above try to present a rather more extended context where the conditional form - $b a$ is used, but again, there is not much here to help a learner understand when and how this form is used in colloquial language. In these examples, the conditional form is used to give instructions; for an anglophone learner, this may seem unnatural as instructions are not typically phrased this way in English. In fact, in Minna no Nihongo, three other conditional structures (i.e., -to, ta-form+ra, and -nara) are introduced by the end of this same lesson, but except for a short 'note' in the grammatical explanations, the semantic and pragmatic differences between the four structures are not addressed. Therefore, the grammatical instructions provided in this textbook for this particular grammar structure are unclear at best and the exercises, such as the ones shown above, do little to allow the learner to master the meaning and the use of conditional structures in Japanese.

\section{The research}

Against the background we have analysed above, and the uncertainty regarding the value of pedagogic grammar which was evident from our review of the literature, we set out to investigate the views on grammar of a sample of 93 UK anglophone university students of Japanese at upper-beginner lower-intermediate level. Given the lack of existing research in this area, our focus was exploratory, guided by the following broad questions:

1. What do these learners understand to be the 'meaning' or value of grammar? Do they see it as differentially helpful for different language skills? 
2. How do learners prefer to receive grammatical instruction? Do they generally prefer a teacher-guided deductive approach or a student-centred inductive approach, or a mixture of both? Do they want instruction to be primarily in the $\mathrm{L} 1$, the $\mathrm{L} 2$ or a mixture of both?

3. What kinds of exercises do they find most useful?

4. What else do they feel teachers could do to support their grammar learning?

\section{The questionnaire}

Data were collected through an online questionnaire using esurv.org. In order to obtain as many responses as possible without losing participants' attention, the number of questions was kept to a minimum, and a 5-star 'rating', similar to online reviews, was used instead of the conventional Likert scale. Every effort was made to ensure the statements in the questionnaire were worded in plain, non-technical language. The questionnaire, shown in the Appendix, comprised two parts. In the first part, there were four short-answer questions that asked about personal information, in particular, the participant's native language, age, past experience of studying a foreign language, and duration of studying Japanese. In the second part, there were four questions, either with multiple-choice items or requiring rating, followed by a final open-ended question. Question 1 focused on why students might feel grammar was helpful or unhelpful, with specific focus on whether they found it helpful for particular skills. Question 2 focused on classroom approaches, and the degree to which students favoured teacher-centred explanation or a more student-centred approach. Question 3 focused on the language of instruction while Question 4 asked respondents to rank seven different types of practice exercise. Question 5 was open-ended, asking the students to say how teachers might make Japanese grammar learning more effective.

\section{Participants}

The 93 participants were all specialising in Japanese language in three British universities. The majority of participants were from the institution where the author worked. Data were collected gradually over four years (2014-2017). The participants' ages ranged from 18 to 29 with an average of 21 . They were studying Japanese as single Honours or as a combined subject and had an average of 6.6 contact hours per week. They had already studied Japanese for one to three academic years, each year comprising 24 weeks of instruction. The courses that they were enrolled in were upperbeginner to lower-intermediate levels (CEFR A2-B1). 81 participants were native English ( $n=71$ ) or bilingual $(n=10)$ speakers. The remaining 12 participants were native speakers of Norwegian ( $n=4)$, Russian ( $n=3)$, Italian $(n=2)$, Chinese $(n=1)$, Thai $(n=1)$, and French $(n=1)$. Regarding their L2 experience, 81 participants had more than one year's experience of studying another language; for 12 , Japanese was their first $L 2$.

\section{Data analysis}

The data collected were first analysed using SPSS version 22 to identify any effects for participants' L1 (i.e. English or other), their previous experience of studying a FL, or the duration of their Japanese study (1-2 years or 2-3 years). However, differences were not 
significant for any of these variables, so the results were analysed as a whole. For the final open-ended question, NVivo version 11.4.1 was used to assist content analysis. First, the author classified the open-ended responses into categories. A second researcher then looked at the data and coding, and the two researchers discussed any discrepancies. The revised categories were used for the analysis.

\section{Results}

Question 1 asked the participants what they felt grammar 'meant' or was useful for. As this was a 'check all that apply' question with nine options, frequencies were calculated for each option. $90.3 \%$ of the options ticked were those which stated that grammar was useful (options $a, b, c, d$ and e), confirming previous studies that learners tend to value grammar. No participants ticked item i 'I do not think it is necessary to study grammar' and the percentage response to the other items stating that grammar was not very useful (items $f, g$ and $h$ ) received low levels of agreement. In particular, the majority of participants thought that grammar was useful for writing (94.6\%) and reading (83.9\%), and a lesser proportion thought it was useful for listening (76.3\%) and speaking (65.6\%). Their view that grammar is beneficial for improving the skills coincides with the findings reported in Loewen et al. (2009). The lower score for speaking may well be related to the fact that $26 \%$ agreed with the statement that grammar is not useful when speaking as they could not think and speak at the same time. Table 1 shows the number and percentage of respondents who agreed with each item.

Table 1. Results for question 1.

\begin{tabular}{|l|c|c|}
\hline \multicolumn{1}{|c|}{ The role of Japanese grammar } & N & Percentage \\
\hline a. Grammar is useful for reading. & 78 & $83.9 \%$ \\
\hline $\begin{array}{l}\text { b. Grammar is useful for writing. } \\
\text { c. Grammar is useful for listening. }\end{array}$ & 71 & 91 \\
\hline $\begin{array}{l}\text { d. Grammar is useful for speaking. } \\
\text { knowledge. }\end{array}$ & 53 & $65.6 \%$ \\
\hline $\begin{array}{l}\text { f. Grammar is not very useful: Meaning can be } \\
\text { deduced from the context. }\end{array}$ & 9 & $57.0 \%$ \\
\hline $\begin{array}{l}\text { g. Grammar is not very useful: I forget parts of it. } \\
\text { h. Grammar is not very useful: I cannot think and } \\
\text { speak at the same time. }\end{array}$ & 5 & $5.7 \%$ \\
\hline $\begin{array}{l}\text { i. I do not think it is necessary to study grammar. } \\
\text { Total }\end{array}$ & 0 & $24.8 \%$ \\
\hline
\end{tabular}


Question 2 asked how the participants preferred to be taught new grammar. $57 \%$ preferred the teacher to explain the new grammar and then to examine the examples by themselves. $23.7 \%$ had a more passive attitude and preferred the teacher to explain the rules as well as the examples. $19.4 \%$ preferred to attempt to discover the rules for themselves before listening to the teacher's explanation. Again, this reflects a tendency highlighted in other research for learners to rely on the teacher to understand grammar and favour less the more student-centred 'discovery' approaches to grammar.

Question 3 asked participants about their language preference when receiving instructions. $83.9 \%$ preferred a mixture of Japanese and English where grammar is taught primarily in Japanese, but with English used where understanding might be difficult. 9.7\% preferred Japanese only and 6.5\% preferred English only.

Question 4 asked the participants to rate seven different types of exercise on a scale of 1 to 5 as to their usefulness when learning new grammar. 91 participants answered this question. Table 2 shows the mean score out of five and the standard deviation for each option. The most helpful exercise by far for learners was item a, to read example sentences. The next most popular exercises were items e (oral exercises) and $f$ (translation exercises). In contrast, item $d$ (rewriting and gap-filling exercises) was the least popular.

Table 2. Results for question 4.

\begin{tabular}{|l|c|r|}
\hline \multicolumn{1}{|c|}{ Type of exercise } & Mean & SD \\
\hline a. Read example sentences that have the new grammar & 4.40 & 0.79 \\
\hline $\begin{array}{l}\text { b. Read short or medium-long passages that have the } \\
\text { new grammar. }\end{array}$ & 3.55 & 1.01 \\
\hline c. Do listening exercises that have the new grammar. & 3.68 & 1.09 \\
\hline $\begin{array}{l}\text { d. Do simple rewriting and gap-filling exercises } \\
\text { e. Oral exercises that make you produce the new } \\
\text { grammar. }\end{array}$ & 3.41 & 1.11 \\
\hline $\begin{array}{l}\text { f. Translation exercises } \\
\text { g. Exercises that make you imagine a situation and } \\
\text { produce sentences using the new grammar. }\end{array}$ & 3.79 & 0.96 \\
\hline
\end{tabular}

Question 5 was an open-ended question that asked the participants what they thought teachers could do to make their learning of Japanese grammar more efficient. There were 77 comments, which were then classified into six categories using NVivo: practice, explanation, revision, material, curriculum, and other. Comments focused mostly on providing practice $(n=30)$ and explanation $(n=28)$. Of the former, half referred to the need to practise grammar through language skills (reading, writing, listening, speaking); as one respondent commented, it is '... useful to get a balance between 
writing, reading, speaking and listening when trying to completely learn the new grammar'. Some referred to practising grammar through skills in general, and others referred to a specific skill: speaking $(n=4)$, listening $(n=3)$, reading $(n=2)$, and writing $(n=1)$. Other comments suggested the need for 'more exercises which force us to use the new grammar'. A few suggested translation exercises $(n=3)$, activities that are engaging ( $n=3)$, and drills ( $n=3$ ).

Many comments on explanations referred to content $(n=12)$ and manner $(n=10)$ of explanations. On content, some asked for more examples $(n=5)$, e.g. 'I learn by examples, so I like to see many', while others asked for background information $(n=3)$, where 'background' seemed to refer to more detailed semantic and pragmatic information, e.g. 'I think it's best to fully understand the structure of the grammar point and understand the "meaning", but more so the feeling behind it and in what context is it used for.' There were also suggestions that it would be useful to compare the grammatical structure in question with English $(n=2)$ and to explain the differences between similar structures $(n=2)$.

Regarding the manner of explanation, some asked for grammar to be explained clearly $(n=3)$, to be explained before going onto examples or exercises $(n=3)$, to be explained in simple terms without using terminology $(n=2)$, and to be explained in English to ensure understanding $(n=2)$. Other comments suggested spending more time on grammar $(n=4)$, e.g. 'give us more time to take in the information'. Finally, regarding revision $(n=8)$, respondents suggested revisiting grammar $(n=6)$, e.g. 'some extra time could be dedicated to revisiting grammar which has already been covered to ensure it has been learned and understood,' and a few suggested having more tests $(n=2)$.

\section{Discussion}

In line with previous studies relating to other target languages, our JFL learners' responses suggested that they valued pedagogic grammar and considered it useful. They tended to prefer a deductive approach where teachers explain new grammatical structures rather than being asked to discover the rules for themselves. However, the majority of learners also reported that they then wanted to get to grips with understanding examples of the structure on their own rather than have the teacher explain them. They preferred teachers to use a mix of languages when explaining grammar, using the shared L1 when explaining things that might be difficult for them to understand in the L2. These responses generally suggest some alignment with current classroom practices commonly employed in JFL.

There seemed, however, to be some mismatch between learners' preferences and the typical 'traditional' approach, as exemplified earlier in the JFL textbooks. Learners' comments in answer to Question 5 suggested some desire to better understand the meaning and use of grammatical structures. This comes as little surprise given the heavy focus on decontextualized form in the textbooks. The low average rating of mechanical exercises (Question 4 item $d, M=3.41$, the lowest score of the seven exercise types) shows that learners do not consider them as very useful in their learning and this view concurs with the aforementioned criticism on the pedagogic values of such exercises (DeKeyser 1998, Celce-Murcia 2007, Larsen-Freeman 2014).

The high rating for reading example sentences (Question 4 item a, $M=4.40$ ) may also reflect their desire to better understand the grammatical structures. Surveying 
examples was a distinct preference expressed by learners in Loewen et al. (2009) and suggests that it is one of learners' strategies when making sense of grammar. The particularly high rating in the case of Japanese is perhaps reflective of how difficult Japanese is for anglophone learners. It shows that the grammatical explanations and examples given in textbooks are not enough for learners to reach a level of understanding that they could feel confident about. Following Larsen-Freeman (2014), we suspect that learners do want to engage in searching for patterns of meaning by surveying examples to complement the (limited) explanations offered in textbooks and/or by the teacher.

Learners reported wanting to practise new grammatical structures through the different language skills (Question 1). Their urge to use new grammar also suggests that they seek opportunities to practise and experiment with target structures. Certainly, there was a strong preference for oral practice (Question 4 item e, $M=3.93$ ). This could be interpreted as support for more communicative activities which trigger students' use of the target structure ('make you produce the new grammar') in the completion of a 'task', rather than in decontextualised drills. In the same vein, there was also some support for exercises that linked target structures to 'situations' (Question 4 item g, $M=3.89$ ) and in particular, engaged students' imagination.

It is interesting, though, that the respondents felt on the one hand, that they wanted to practise grammar most through speaking (Question 4 item e), but on the other hand, believed that grammar was more useful for skills other than speaking (Question 1 items a-d). The strong support for oral exercises when learning new grammar may be accounted for by the complexity of the Japanese writing system. Japanese uses two syllabaries (hiragana and katakana) and Chinese characters called kanji. Several hundred kanji are already introduced at the upper-beginner level and learners have not only to be able to read Japanese correctly in order to perform a written task, but also to pay close attention to orthography when they write. Therefore, they may prefer to practise new grammar orally and save the time and attention that it would take to write out sentences. Alternatively, the popularity of oral exercises, revealed in answers to Question 4 item e, may be another reflection of their interest in learning to 'use' the language orally. Our findings unfortunately do not provide any further information to allow us to explore this more fully.

Some comments in response to Question 5 asked the teacher to provide more information; for example, giving more background information on the target structure $(n=3)$; explaining the differences between similar L2 structures $(n=2)$; and making comparisons with the L1 $(n=2)$. A desire to have clear and detailed explanations on grammar was also observed in Loewen et al. (2009). Although the number of respondents in these cases was small with respect to the total number of participants in this study, they do suggest that some students were keen to seek out associations and make comparisons with existing L1 and L2 knowledge, actions identified by various authors including Larsen-Freeman (2014) as potentially helpful language learning strategies.

Translation in particular was seen by the students as a useful exercise for learning new grammatical structures (Question 4 item $f, M=3.91$ ); indeed, it had the second highest score of the seven exercise types. Though translation as a tool for developing grammatical mastery, rather than as a communicative language skill, lost favour in language teaching due to its association with the Grammar-Translation 
method, it is now being recognised that exploring correspondences between TL and L1 may be helpful for understanding the meaning and use of target structures in greater depth. Recent studies such as G. Cook (2010) or Korosec (2013) have indeed reported on the benefits of translation as a means of practising grammar. However, including translation as practice simply to align with learners' expectations calls for caution; learners' preference for translation may reflect a potentially limiting belief that $\mathrm{FL}$ learning is 'merely' a matter of translating from the L1 (Horwitz 1988). Further, given that there are many structures in the $\mathrm{L} 2$ whose meaning and/or use do not correspond easily to L1 structures - and this is particularly the case for anglophone learners learning Japanese - teachers need to reflect carefully on when and how translation is best used to support grammar learning. Nevertheless, it may be that judicious use of translation particularly into the L1 - may help students of Japanese explore (and indeed practise) more fully Larsen-Freeman's (2014) full range of form, meaning and use of grammatical structures.

\section{Limitations of this study}

The present study was inevitably limited by its relatively small number of respondents and its restricted but exploratory focus. It would now be helpful to pursue qualitative research based on in-depth interviews or focus groups with JFL learner groups similar to those surveyed here, in order to explore in far more detail how they view the role of grammar in their JFL learning; what challenges they experience and what strategies they adopt to address them, and in particular, whether our speculation above, that students appeared to want to look at JFL grammar more broadly (covering not just 'form' but 'meaning' and 'use' too) and more actively incorporating oral practice, would be borne out. It would also be helpful to undertake a fuller survey with a larger set of respondents, possibly from a wider range of learning contexts and perhaps with a wider range of characteristics. It is worth noting here that the UK may constitute a 'special case' in terms of FL learning, as it has seen a decline in the uptake of modern languages in secondary schools in recent years (Tinsley and Board 2017). Unlike in other countries where language learning (typically of L2 English) is fairly universal, it is not rare for JFL students in the UK to have never studied any language before. Previous language learning experiences are said to influence learning styles, strategies and preferences (Pazaver and Wang 2009), but we were not here able to make any observations on the possible influence of previous language learning, due to the low numbers of respondents in the present study.

\section{Conclusion}

This study looked into JFL learners' perceptions regarding the meaning of grammar, formal instruction, and the process of learning grammatical structures. Our results confirmed previous studies that learners do value grammar and formal instruction, and that they look to their teacher in the first instance to provide effective explanation. These upper-beginner lower-intermediate JFL learners also seemed to want more teaching focused on understanding meaning and use of grammatical structures.

We suggest that in the case of a 'difficult' language such as Japanese for L1 English learners, more FonFs that incorporates different learning strategies such as 
pattern recognition and making associations with the shared $\mathrm{L} 1$ and other structures in the TL, as suggested by Larsen-Freeman (2014), might be beneficial to, and valued by, many JFL learners. Many JFL programmes continue to employ a structural syllabus where FonFs is mainly directed towards the morphosyntactic properties of the target structures, but the responses of the learners in this study suggest that more FFI directed towards semantic and pragmatic aspects of the target structures might be well received, along with opportunities for practice in a range of skills. We hope that as JFL pedagogy shifts towards a more communicative syllabus, at least in Europe, FonFs will gradually be complemented with FonF to provide learners with a more balanced approach to grammar as part of their Japanese learning.

\section{Note}

1. From Learn Japanese.

https://www.reddit.com/r/LearnJapanese/comments/238es9/what_do_you_think_the_ main_challenges_of_learning/

\section{References}

3A Corporation. 2013. Minna no Nihongo Shokyu 2 Honsatsu. $2^{\text {nd }}$ edition. Tokyo: 3A Corporation.

Borg, M. 2001. Key concepts in ELT. Teachers' beliefs. ELT Journal 55, no.2: 186-188. doi: $10.1093 /$ eltj/55.2.186

Borg, S. 1998. Teachers' pedagogical systems and grammar teaching: a qualitative study. TESOL Quarterly 32, no.1: 9-38. doi: 10.2307/3587900

Borg, S. and A. Burns. 2008. Integrating grammar in adult TESOL classrooms. Applied Linguistics 29, no.3: 456-482. doi: 10.1093/applin/amn020

Broady, E. and N. Dywer. 2008. Bringing the learner back into the process: identifying learner strategies for grammatical development in independent language learning. In Language Learning Strategies in Independent Settings, ed. S. Hurd and T. Lewis, 141-158. Bristol: Multilingual Matters.

Burgess, J. and S. Etherington. 2002. Focus on grammatical form: Explicit or implicit? System 30, no.4: 433-458. doi: 10.1016/S0346-251X(02)00048-9

Celce-Murcia, M. 1990. Discourse analysis and grammar instruction. Annual Review of Applied Linguistics 11: 135-151. doi: 10.1017/S0267190500002002

Celce-Murcia, M. 2007. Towards more context and discourse in grammar instruction. TESL-EJ 11, no.2.

Cook, G. 2010. Translation in Language Teaching: An Argument for Reassessment. Oxford: Oxford University Press.

DeKeyser, R.M. 1998. Beyond focus on form, cognitive perspectives on learning and practicing second language grammar. In Focus on Form in Classroom Second Language Acquisition, edited by C. Doughty and J. Williams, 42-63. Cambridge, Cambridge University Press.

Ellis, N.C. 2005. At the interface: Dynamic interactions of explicit and implicit language knowledge. Studies in Second Language Acquisition 27: 305-352. doi: 10.1017/S027226310505014X

Ellis, R. 2001. Introduction: Investigating form-focused instruction. Language Learning 51: 1-46. doi: 10.1111/j.1467-1770.2001.tb00013.x 
Ellis, R. 2006. Current issues in the teaching of grammar: An SLA perspective. TESOL Quarterly 40, no.1: 83-107. doi: 10.2307/40264512

Ellis, R. 2016. Focus on form: A critical review. Language Teaching Research 20, no.3: 405-428. doi: $10.1177 / 1362168816628627$

Erlam, R. 2003. The effects of deductive and inductive instruction on the acquisition of direct object pronouns in French as a second language. The Modern Language Journal 87, no.2: 242-260. doi: 10.1111/1540-4781.00188

Harley, B. 1989. Functional grammar to French immersion: A classroom experiment. Applied Linguistics 70: 331-359. doi: 10.1093/applin/10.3.331

Hawkey, R. 2006. Teacher and learner perceptions of language learning activities. ELT Journal 60: 242-252. doi: 10.1093/elt/ccl004

Horwitz, E. 1988. The beliefs about language learning of beginning university foreign language students. Modern Language Journal 72, no.3: 283-294. doi: 10.1111/j.1540-4781.1988.tb04190.x

Japan Foundation, 2015. 2015-nendo Nihongo Kyouiku Kikan Chosa Kekka (Survey Report on Japanese-Language Education Abroad 2015). https://www.jpf.go.jp/j/project/japanese/survey/area/country/2017/uk.html Accessed 2 December 2018.

Kern, R. 1995. Students' and teachers' beliefs about language learning. Foreign Language Annals 28, no.1: 71-92. doi: 10.1111/j.1944-9720.1995.tb00770.x

Korosec, M. 2013. Teaching grammar through translation. In Translation in Language Teaching and Assessment, edited by D. Tsagari and G. Floros, 23-40. Newcastle upon Tyne, Cambridge Scholars Publishing.

Klapper, J. 2005. Teaching grammar. In Effective Teaching and Learning in Modern Languages, edited by J.A. Coleman and J. Klapper, 67-74.

Krashen, S. 1981. Bilingual education and second language acquisition theory. In Schooling and Language Minority Students: A Theoretical Framework, 51-79. California State Department of Education.

Krashen, S. 1985. The Input Hypothesis: Issues and Implications. New York, Longman.

Larsen-Freeman, D. 1991. Consensus and divergence on the content, role, and process of teaching grammar. In Georgetown University Round Table on Languages and Linguistics 1991: Linguistics and language pedagogy: The state of the art, edited by J. Alatis, 260-272. Washington, DC: Georgetown University Press.

Larsen-Freeman, D. 2001. Teaching grammar. In Teaching English as a Second or Foreign Language (3rd edition), edited by M. Celce-Murcia, 251-266. Boston, MA: Thomson/Heinle.

Larsen-Freeman, D. 2003. Teaching language: From Grammar to Grammaring. Boston, MA: Thomson/Heinle.

Larsen-Freeman, D. 2014. Teaching grammar. In Teaching English as a Second or Foreign Language (4th edition), edited by M. Celce-Murcia, D. Brinton, and M.A. Snow, 256-270. Boston, MA: National Geographic Learning/Cengage Learning.

Liao, M., and Wang, H. 2009. Perception differences of EFL teachers and students in grammar instruction and error correction. English Teaching and Learning 31, no.1: 101-146.

Loewen, S., S. Li, F. Fei, A. Thompson, K. Nakatsukasa, S. Ahn, and X. Chen (2009). Second language learners' beliefs about grammar instruction and error 
correction. The Modern Language Journal 93, no.1: 91-104. doi:

10.1111/j.1540-4781.2009.00830.x

Long, M. 1991. Focus on Form: A design feature in language teaching methodology. In Foreign Language Research in Cross-Cultural Perspective, edited by K. de Bot, R. Ginsberg and C. Kramsch, 39-52. Amsterdam: Benjamins. doi: 10.1075/sibil.2.07lon

Macrory, G. 2000. Learning to teach grammar in the modern foreign languages classroom: Some implications for initial teacher education. Research in Education 64, no.1: 1-11. doi: 10.7227/RIE.64.1

Mitchell, R. 2000. Applied linguistics and evidence-based classroom practice: The case of foreign language grammar pedagogy. Applied Linguistics 21, no.3: 281-303. doi: 10.1093/applin/21.3.281

Montgomery, C., and Eisenstein, M. 1985. Reality revisited: An experimental communicative course in ESL. TESOL Quarterly 19: 317-334. doi: $10.2307 / 3586832$

Mori, Y. 1999. Epistemological beliefs and language learning beliefs: What do language learners believe about their learning? Language Learning 49: 377-415. doi:10.1111/0023-8333.00094

Norris, J.M., and L. Ortega. 2000. Effectiveness of $L 2$ instruction: A research synthesis and quantitative meta-analysis. Language Learning 50: 417-528. doi: 10.1111/0023-8333.00136

Odlin, T. 1994. Introduction. In Perspectives on Pedagogical Grammar, edited by T. Odlin, 1-22. Cambridge: Cambridge University Press.

Pazaver, A. and Wang, H. 2009. Asian students' perceptions of grammar teaching in the ESL classroom. The International Journal of Language Society and Culture 27: 27-34. Accessed 2 December 2018.

http://www.academia.edu/4549913/Asian_Students_Perceptions_of_Gramma r_Teaching_in_the_ESL_Classroom

Peacock, M. 1998. Exploring the gap between teachers' and students' beliefs about 'useful' activities for EFL. International Journal of Applied Linguistics 8, no.2: 233-250. doi: 10.1111/j.1473-4192.1998.tb00131.x

Richards, J.C. and T.S. Rodgers. 2001. Approaches and Methods in Language Teaching. $2^{\text {nd }}$ edition. Cambridge: Cambridge University Press.

Rutherford, W., and M. Sharwood Smith. 1985. Consciousness-raising and universal grammar. Applied Linguistics 6:274-82. doi: 10.1093/applin/6.3.274

Schmidt, R., and S. Frota 1986. Developing basic conversational ability in a second language: A case-study of an adult learner. In Talking to Learn: Conversation in Second Language Acquisition, edited by R. Day, 237-326. Rowley, MA: Newbury House.

Schulz, R. 1996. Focus on form in the foreign language classroom: Students' and teachers' views on error correction and the role of grammar. Foreign Language Annals 29, no.3: 343-364. doi: 10.1111/j.1944-9720.1996.tb01247.x

Schulz, R. 2001. Cultural differences in student and teacher perceptions concerning the role of grammar teaching and corrective feedback: USA-Colombia. The Modern Language Journal 85, no.2: 244-258. doi: 10.1111/0026-7902.00107 
Swain, M. 1985. Communicative competence: Some roles of comprehensible input and comprehensible output in its development. In Input in Second Language Acquisition, edited by S. Gass and C. Madden, 235-253. Rowley, MA Newbury.

The Japan Times. 2011. Genki. Second edition. Tokyo: Japan Times.

Tinsley, T., and K. Board. 2017. Language Trends Survey: Language Teaching in Primary and Secondary Schools in England Survey Report. British Council. Accessed 2 December 2018.

https://www.britishcouncil.org/sites/default/files/language_trends_survey_20 17_0.pdf

VanPatten, B. 1990. Attending to form and content in the input: An experiment in consciousness. Studies in Second Language Acquisition 12, no.3: 287-301. doi:10.1017/S0272263100009177

Yang, N. 1999. The relationship between EFL learners' beliefs and learning strategy use. System 27, no.4: 515-535. doi:10.1016/S0346-251X(99)00048-2 


\section{Appendix. Questionnaire on Japanese grammar and grammar lessons}

In Section 1, please tell us about yourself and your experience with Japanese.

Q1. What is/are your native language/s?

Q2. How old are you?

Q3. What languages have you studied besides Japanese and how long?

Q4. How long have you been studying Japanese?

In Section 2, please tell us how you feel about Japanese grammar and the way you have been learning it.

Q1. In your opinion, what is the meaning of studying Japanese grammar? (Check all that apply to you)

a. It helps me with my reading: if I know the grammar, I can understand the text better.

b. It helps me with my writing: if I know the grammar, I can write more accurately and express myself better.

c. It helps me with my listening comprehension.

d. It helps me when I speak: I can construct my sentences better while I speak or interact with someone in Japanese.

e. It helps me organise my knowledge of Japanese.

f. Actually, I don't rely much on grammar when I read, because I normally understand from the context.

g. Actually, I'm not sure if my knowledge of grammar helps, because I forget parts of it and I'm never sure of which form to use.

h. It doesn't help me much when I am interacting with someone, because I don't have time to think and speak at the same time.

i. To tell the truth, I think studying grammar is not really necessary, because you can usually understand the meaning from the context.

Q2. How do you prefer to learn new grammar in the classroom? (Select one answer)

a. I want the teacher to explain everything, including reading the examples and explaining what they mean.

b. I want the teacher to explain the grammar, then, I want to try understanding the examples on my own.

c. I want to try discovering the rules first, and later listen to the teacher's explanation.

Q3. In what language do you prefer to receive lessons on grammar? (Select one answer)

a. In Japanese, although I may not understand all of it.

b. In English

c. Partially in Japanese (where the teacher thinks we can understand)

Q4. How would you rate the usefulness of the following types of exercises when you learn new grammar?

a. Read example sentences that have the new grammar

b. Read short or medium-long passages that have the new grammar.

c. Do listening exercises that have the new grammar.

d. Do simple rewriting and gap-filling exercises

e. Oral exercises that make you produce the new grammar.

f. Translation exercises

g. Exercises that make you imagine a situation and produce sentences using the new grammar.

Q5. What do you think teachers can do to make your learning of Japanese grammar more effective? 